\title{
Behaviour of Condensation for High Steam Energy and Water in Vertical Annular Channel
}

\author{
W.M.Faizal Wan Abd Rahim ${ }^{1,2}$, M.Zamri Zainon ${ }^{2,3}$, and N.Nazri Nik Ghazali ${ }^{2}$ \\ ${ }^{1}$ Mechanical Department of Engineering Technology, Faculty of Engineering Technology, University Malaysia Perlis,02100 Padang \\ Besar, Perlis, Malaysia \\ ${ }^{2}$ Department of Engineering, Faculty of Engineering, University of Malaya, 50603 Kuala Lumpur, Malaysia \\ ${ }^{3}$ Center of Energy Science, University of Malaya, 50603 Kuala Lumpur, Malaysia
}

\begin{abstract}
In this paper, condensation for high steam energy in vertical annular channel was investigated. Simulations were carried out to investigate the behaviour of condensation using FLUENT 14.5 in static water and steam velocity $0.2 \mathrm{~ms}^{-1}$. The results show that, the steam outer surface show rapid condensation activity effect from the steam velocity. Due to this effect, further investigate may require to show condensation behaviour with the various steam velocity.
\end{abstract}

\section{Introduction}

Nuclear Power Plant has multiple safety system to ensure three basic system secure function such as controlling the reactor, controlling the fuel and containing the radiation[1].

Consequences of this awareness, proper study need to be carrying out. Referring to the latest accident in the nuclear power plant, such as Fukushima in 2011 will give bad impression to the world wide scale. The main concern for the public on the both either long term and short term to the public health, environment and energy policy and security of the neighbour country.

Safety factor is the most important factor need to focus related to the nuclear reactor. Several factors need to be main focus activity for example rector system and structure and components. Reactor system is the main agenda need to be focus for this study. That is strategies to enhance safety for this RTP upgrading, refurbishment of RTP primary cooling system, refurbishment of RTP instrumentation and control, Neutronics \& Thermal Hydraulic Analysis, Ageing Management Program and Quality Assurance.

Refurbishment of primary cooling system is the main focus for this thesis. Cooling system is the most important system in the nuclear reactor. The most famous phenomena that related to the cooling system failure are the Loss of Coolant Accident (LOCA), where dried liquid on the heating element cannot manage the heat produce by the fuel rod. Radiation contamination not only for safety issue but also affect to the environmental regulation [2-4].

To overcome this issue, condensation in annular channel is the correct prototype to simulate this safety issue. To understand condensation phenomena in the annular channel, all parameter that contribute to the

Corresponding author: wanmohd@unimap.edu.my condensation need to analyse such as condensation heat transfer coefficient, surface contact area and also need to understand flow pattern involve in the particular condition. Condensation also involve in the two-phase phenomena. By understand properties in two-phase flow, condensation can be determined more accurate.

The appreciative of heat transfer knowledge in convection and conduction are compulsory to investigate the nuclear reactor safety system. By looking the basic knowledge of convection, Newton's Law of Cooling,

$$
\mathrm{Q}=\mathrm{hA}\left(\mathrm{T} \_\mathrm{s}-\mathrm{T} \_\mathrm{w}\right)
$$

where $\mathrm{h}=$ convection heat transfer ceoffcient, $\mathrm{W} / \mathrm{m} 2 \mathrm{~K}$, $\mathrm{A}=$ heat transfer surface area, $\mathrm{m}^{2}, \mathrm{~T}_{\mathrm{s}}=$ temperature of the surface, ${ }^{\circ} \mathrm{C}, \mathrm{T}_{\mathrm{w}}=$ temperature of the fluid sufficiently far from the surface, ${ }^{\circ} \mathrm{C}$.

\section{Physical Model}

The condensation model has been investigate experimentally and computationally by many researchers as pervious mentioned. Condensation is a complex field in the heat transfer area. This area involve by two phase, high steam energy (vapor) and liquid (water). The early stages of the condensation phenomena were introduce by Nusselt and the proposed the first theoretical solution to solve heat transfer coefficient by assuming linear temperature profile cross the laminar film thickness liquid.

Condensation for the purpose in nuclear safety, these phenomena mostly encounter inside the containment. The behaviour inside containment, condensation phenomena will change and directly affect the pressure, temperature and local mixture concentration. 
Condensation in annular channel can be classified into 2 main areas. Firstly, Direct Contact Condensation (DCC) or Bubble Condensation, these phenomena usually used to studies in the Nuclear Safety. Secondly, condensation occurs on the surface (plate) usually used to studies for heat exchanger. These two phenomena occur in the same condensation situation.

Based on the statement above, the important of the condensation need to be focus. Numerical method or computational approaches currently become famous nowadays to analyse phase change phenomena[5]. Many researcher studies the condensation in high speed velocity as steam plume condensation [6-9]. Steam Injector (SI) is the passive system in nuclear reactor as a secondary during emergency accident[10]. This article will show the importance of the velocity that affected the condensation in selected value.

\section{Mathematical Models}

In this research, Volume of Fraction (VOF) method in Mathematical Model will be used to calculate the void fraction of each fluid along the domain was tracked to understand condensation behaviour [11]. Interface mass transfer was tracked by using the thermal equilibrium model. The governing equation of continuity, momentum, energy and the interface model used are presented in the following sections.

\subsection{Mass Conservation Equation}

The mass conservation equation describes the mass flux ration into and out of a control volume and the accumulation in a corresponding control volume. For the qth phase, this equation has the following form:

$$
\frac{1}{P_{q}}\left[\frac{\partial}{\partial t}\left(\alpha_{q} P_{q}\right)+\nabla \cdot\left(\alpha_{q} P_{q} v_{q}\right)=S_{\alpha q}+\sum_{p=1}^{n}\left(\dot{m}_{p q}-\dot{m}_{q p}\right)\right]
$$

The volume fraction equation is not solving for the primary phase and the primary-phase volume fraction is computed based on the following constraints:

$$
\sum_{q=1}^{n} \alpha_{q}=1
$$

where $v_{q}$ is the velocity of phase $\mathrm{q}$ and $\alpha_{q}$ is the volume fraction of the qth phase. $\dot{m}_{q p}$ is the mass transfer from the phase $p$ to the phase $q$. This term is very useful to calculate condensation model in annular channel in understanding void fraction of the high steam energy (vapour).

\subsection{Momentum Transfer Equation}

A single momentum equation is solved throughout the domain, and the resulting velocity field is shared among the phases. The momentum equation, shown below, is dependent on the volume fractions of all phases through the properties $\rho$ and $\mu$.

$$
\begin{aligned}
& \frac{\partial}{\partial t}(\rho v)+\nabla \cdot(\rho v v)= \\
&-\nabla p+\nabla\left[\mu\left(\nabla v+\nabla v^{T}\right)\right]+\rho g+F
\end{aligned}
$$

where $\rho, \mu$ and $v$ are the density, viscosity and velocity of phase in the control volume, respectively.

The term on the right-hand side describe the force acting on the element in the control volume. These are the overall pressure gradient, the stresses, the gravitational force and effect of an external body. Generally speaking, the external body term consists of interfacial forces such as lift, virtual mass forces, surface tension, and etc.

\subsection{Energy Conservation}

The energy equation also share among the phases, is shown below

$$
\frac{\partial}{\partial t}(\rho E)+\nabla \cdot(v(\rho E-p))=\nabla \cdot\left(k_{e f f} \nabla T\right)+S_{\hbar}
$$

The VOF models treat energy, and temperature, $\mathrm{T}$, as mass average variable.

\subsection{Condensation Model}

In this work, the phase change model, which is describe the phase change induced by interphase heat transfer of intrinsic flow, was simulated the condensation model. The models only applicable to the phase change in pure substance and consider heat transfer process on each side of the phase model [12].

For the interfacial area is require to specified volumetric heat transfer coefficient, and has the form

$$
A_{f g}=\frac{6 \alpha_{g}}{d_{g}}
$$

where $d_{g}(\mathrm{~m})$ and $\alpha_{g}$ are the mean diameter and volume fraction of the high steam energy injected to the liquid region, respectively.

Interfacial heat transfer coefficients are requiring them to calculate the heat and mass transfer occur between steam and water phases. 


\section{Simulation Set-ups}

Using the finite volume formulation, twodimensional simulation was carried out to model the condensation behaviour of vapour in annular vertical channel. The numerical approach need to be done to analyse and understand the important of velocity towards condensation in vertical orientation for upwards flow. Even the simulation only carried out single situation, this analyse only to understand the basic affect the velocity towards the condensation.

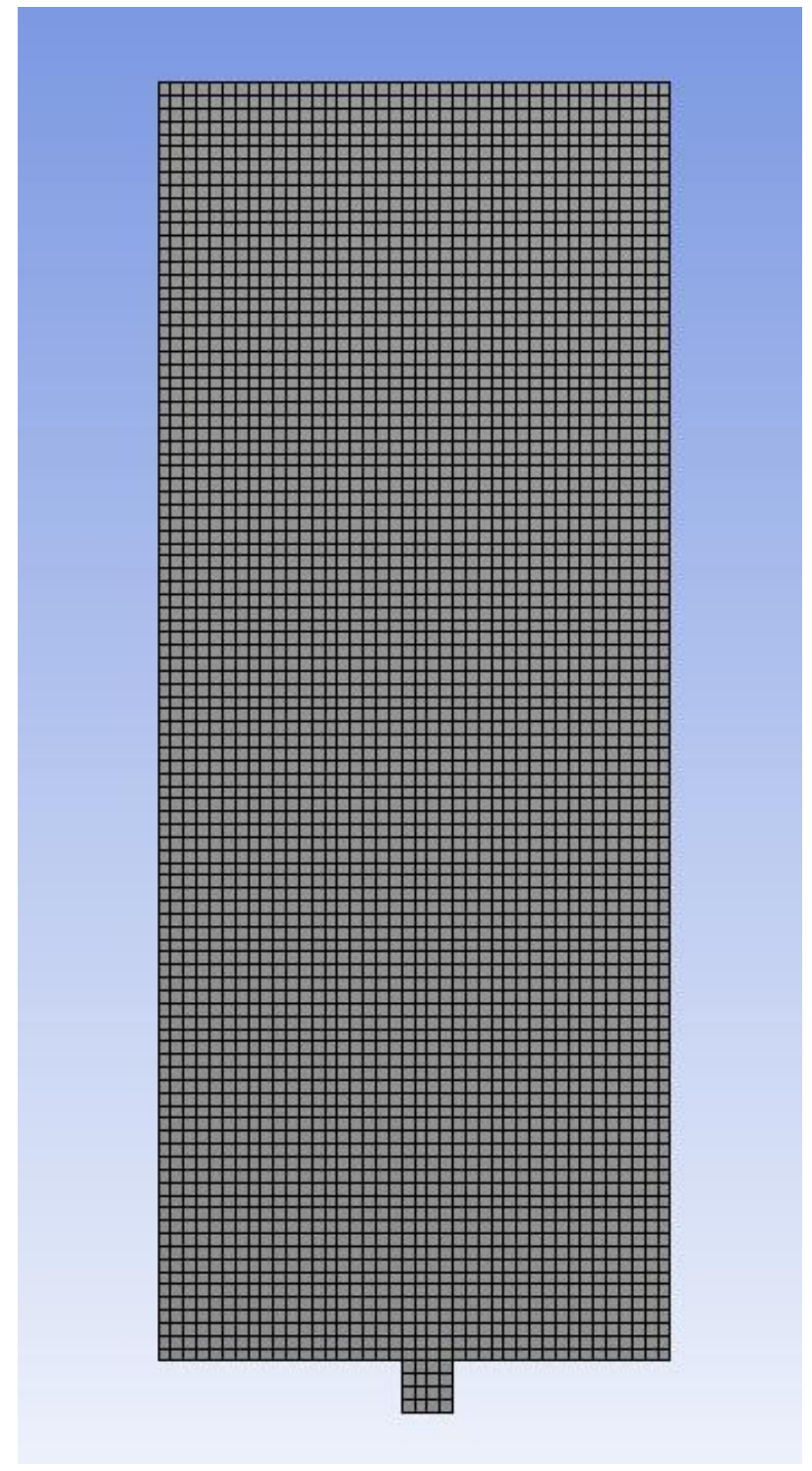

Figure 1: The schematic diagram of annular channel

The SIMPLE algorithm was employed for pressurevelocity coupling and the implicit scheme was used in the time discretization.

All the solution was considered to be fully converged. Here the setting parameter for this simulation shown in Table 1.

Table 1

Parameter used in FLUENT simulation

\begin{tabular}{|c|c|c|c|}
\hline & $\begin{array}{l}\text { Inlet } \\
\text { Velocity } \\
\left(\mathrm{ms}^{-1}\right)\end{array}$ & $\begin{array}{l}\text { Temperature } \\
\text { Inlet } \\
\left({ }^{\circ} \mathrm{C}\right)\end{array}$ & $\begin{array}{l}\text { Tank } \\
\text { Temperature } \\
\left({ }^{\circ} \mathrm{C}\right)\end{array}$ \\
\hline Vapor & 20 & 400 & - \\
\hline Water & - & - & 323.15 \\
\hline
\end{tabular}

The Figure 1 showed the annular channel as shown in with fully dimensional.

The steam inlet was set for fully turbulent with the velocity $20 \mathrm{~ms}^{-1}$ to show the competency the real situation in the nuclear power plant. By using ANSYS FLUENT 14.5, this solver supports the simulation of multiphase flow. The solver also supports the incompressible two phase flow with phase change using VOF model. In order to support the condensation phenomena, energy equation need to be used during this simulation.

This simulation will be run for the $6 \mathrm{sec}$ with the time step size $0.01 \mathrm{~s}$. For 


\section{Results and Discussion}

To understand the behaviour of the condensation, the temperature distribution will be used as indication to understand these phenomena.

(a) $\mathrm{t}=0.2 \mathrm{~s}$

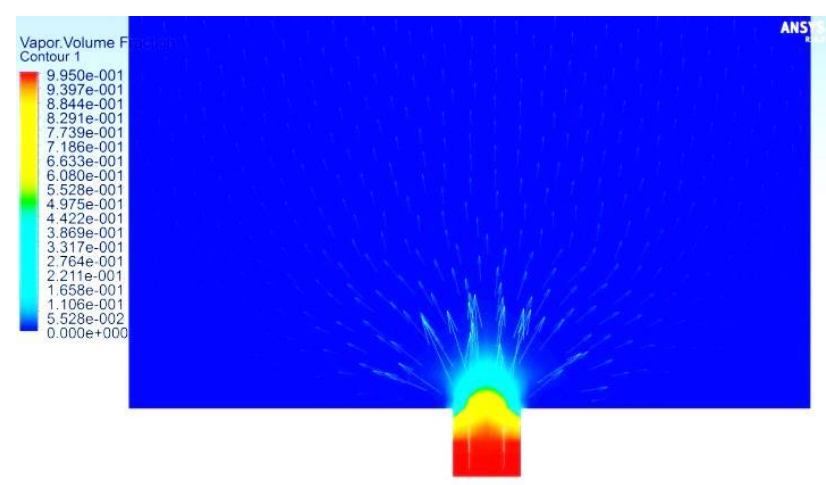

(c) $\mathrm{t}=0.6 \mathrm{~s}$

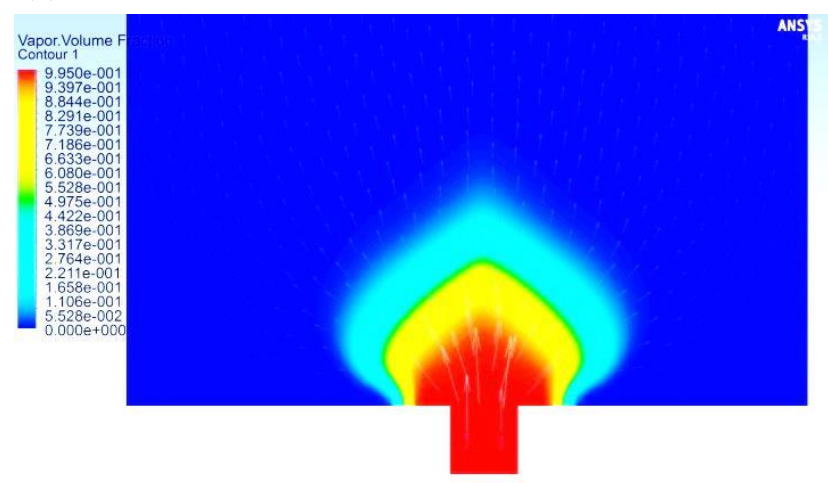

(b) $\mathrm{t}=0.4 \mathrm{~s}$

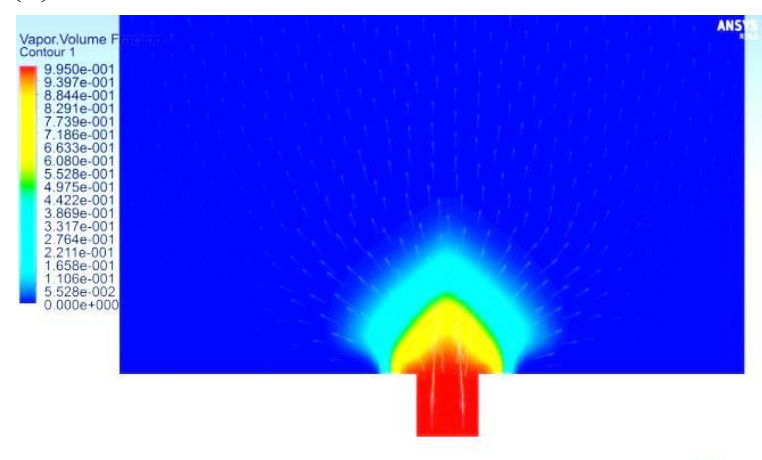

(d) $\mathrm{t}=0.8 \mathrm{~s}$

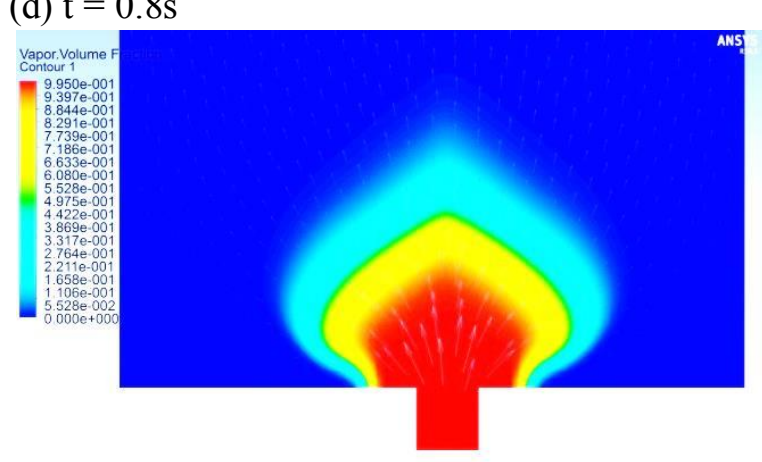

Figure 2: Contour of the void fraction for $\mathrm{t}=0.2 \mathrm{~s}, 0.4 \mathrm{~s}, 0.6 \mathrm{~s}, 0.8 \mathrm{~s}$ 
(a) $\mathrm{t}=0.2 \mathrm{~s}$

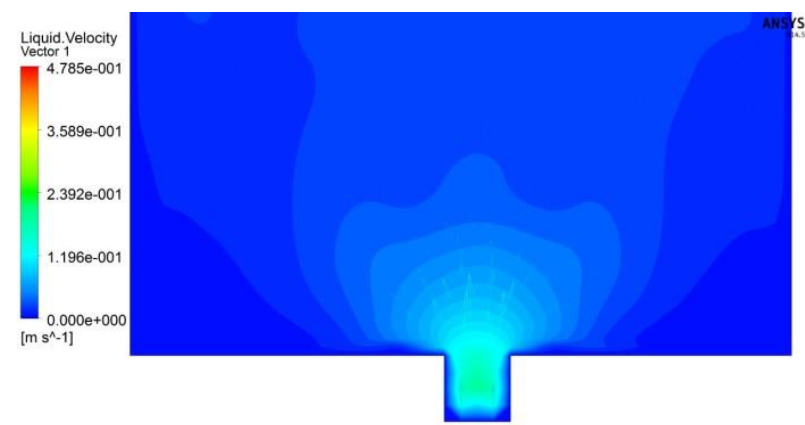

(c) $\mathrm{t}=0.6 \mathrm{~s}$

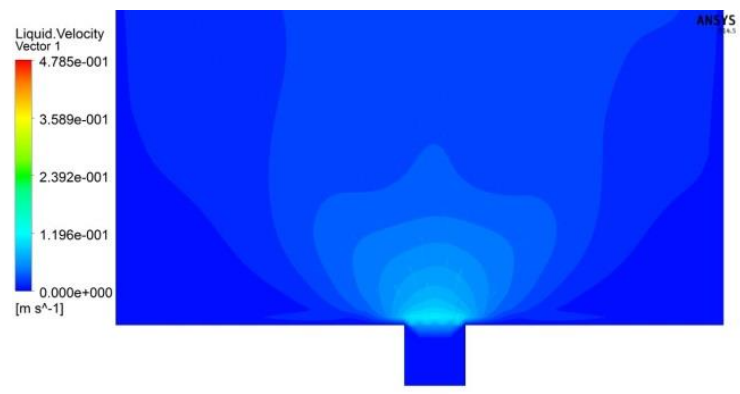

(b) $\mathrm{t}=0.4 \mathrm{~s}$

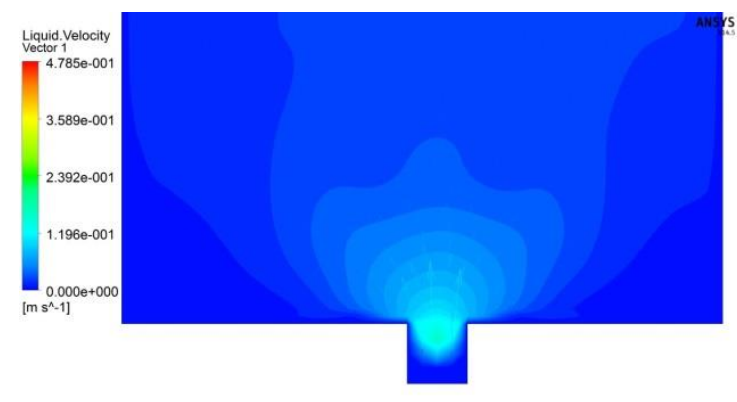

(d) $\mathrm{t}=0.8 \mathrm{~s}$

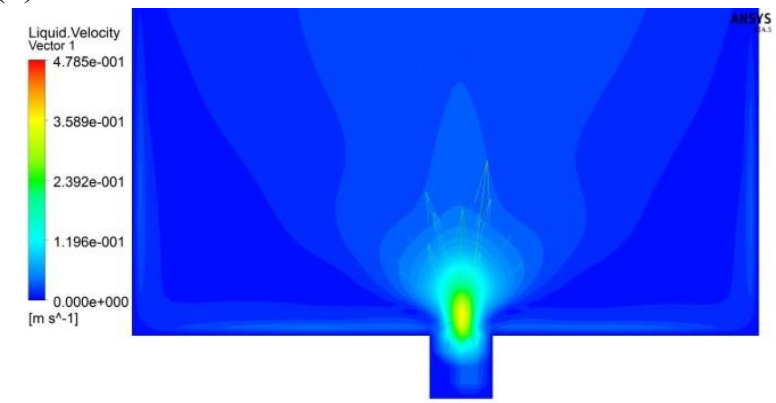

Figure 3: Contour of the liquid velocity for $\mathrm{t}=0.2 \mathrm{~s}, 0.4 \mathrm{~s}, 0.6 \mathrm{~s}, 0.8 \mathrm{~s}$

Figure 2 show the contour of the void fraction for the time $0.2 \mathrm{~s}, 0.4 \mathrm{~s}, 0.6 \mathrm{~s}$ and $0.8 \mathrm{~s}$. These figures show the distribution of the vapour in the liquid region. The boundary area in the figure is the region occur the condensation in the annular channel. This is the important part in this simulation for this analysis.

Figure 3 show the liquid velocity with the same interval time $0.2 \mathrm{~s}, 0.4 \mathrm{~s}, 0.6 \mathrm{~s}$ and $0.8 \mathrm{~s}$. The important of this figure to show vapour trajectory in liquid. For this case of moving liquid and vapour, slip velocity is important to determine.

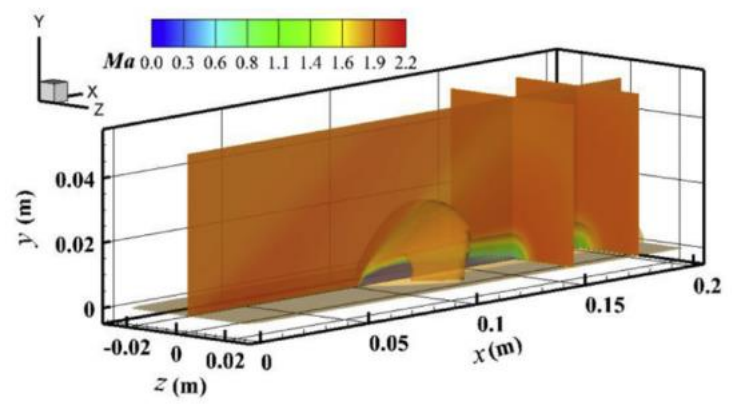

Figure 4: Distribution of Mach number[13]

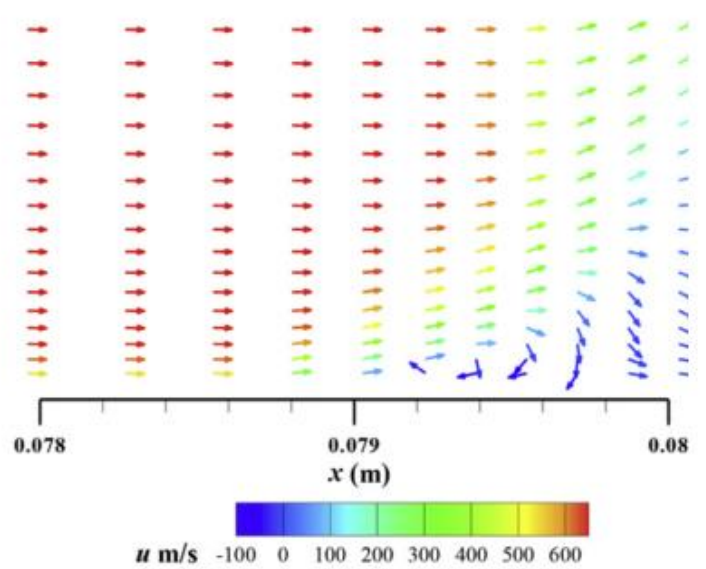

Figure 5: Recirculation Zone[13]

The importance of the velocity been done before by Liu et. al [13]. This author shown that, the velocity or Mach number have main contribution 
affected the condensation in two-phase flow. Phase change phenomena depend on many parameters such as Nusselt Number, Prandlt Number, viscosity and phase of phase. This is main reason, this article to the importance of velocity that need to focus in analysis heat transfer coefficient or phase change phenomena as shown in figure 4 and 5.

This work is supported by the Short-Term Grant Unimap (STG 9001-00559) and Postgraduate Research Grant (PPP) Universiti Malaya (PG206-2015B)

\section{References}

1. Zong, X., et al., Experimental study on the direct contact condensation of steam jet in subcooled water flow in a rectangular mix chamber. International Journal of Heat and Mass Transfer, 2015. 80: p. 448-457.

2. Yeoh, G.H. and J.Y. Tu, Two-fluid and population balance models for subcooled boiling flow. Applied Mathematical Modelling, 2006. 30(11): p. 1370-1391.

3. Ozar, B., et al., Interfacial area transport of vertical upward steam-water two-phase flow in an annular channel at elevated pressures. International Journal of Heat and Mass Transfer, 2013. 57(2): p. 504-518.

4. Evgenidis, S.P. and T.D. Karapantsios, Effect of bubble size on void fraction fluctuations in dispersed bubble flows. International Journal of Multiphase Flow, 2015. 75: p. 163-173.

5. Kharangate, C.R. and I. Mudawar, Review of computational studies on boiling and condensation. International Journal of Heat and Mass Transfer, 2017. 108: p. 1164-1196.
6. Tejedor Sastre, M.T. and C. Vanhille, $A$ numerical model for the study of the difference frequency generated from nonlinear mixing of standing ultrasonic waves in bubbly liquids. Ultrason Sonochem, 2017. 34: p. 881-888.

7. Li, S.Q., et al., Experiment study on steamwater direct contact condensation in water flow in a Tee junction. Applied Thermal Engineering, 2017. 120: p. 99-106.

8. Joshi, J.B., et al., Bubble generated turbulence and direct numerical simulations. Chemical Engineering Science, 2017. 157: p. 26-75.

9. Qu, X.-h., H. Sui, and M.-c. Tian, $C F D$ simulation of steam-air jet condensation. Nuclear Engineering and Design, 2016. 297: p. 44-53.

10. Qu, X.-h. and M.-c. Tian, Acoustic and visual study on condensation of steam-air mixture jet plume in subcooled water. Chemical Engineering Science, 2016. 144: p. 216-223.

11. Xu, Q.G., Liejin., Direct contact condensation of steam jet in crossflow of waterin a vertical pipe. Experimental investigation on condensationregime diagram and jet penetration length. International Journal of Heat and Mass Transfer, 2016. 94.

12. Schlegel, J.P. and T. Hibiki, A correlation for interfacial area concentration in high void fraction flows in large diameter channels. Chemical Engineering Science, 2015. 131: p. 172-186.

13. Liu, H., Y. Guo, and W. Lin, Numerical simulations of spray jet in supersonic crossflows using an Eulerian approach with an SMD model. International Journal of Multiphase Flow, 2016. 82: p. 49-64. 